\title{
Outcome of surgically resected mandibular ameloblastoma
}

\author{
Md. Habibul Haque, Quazi Billur Rahman, Shamiul Alam, Gokul Chand Kundu and \\ Ashik Abdullah Imon
}

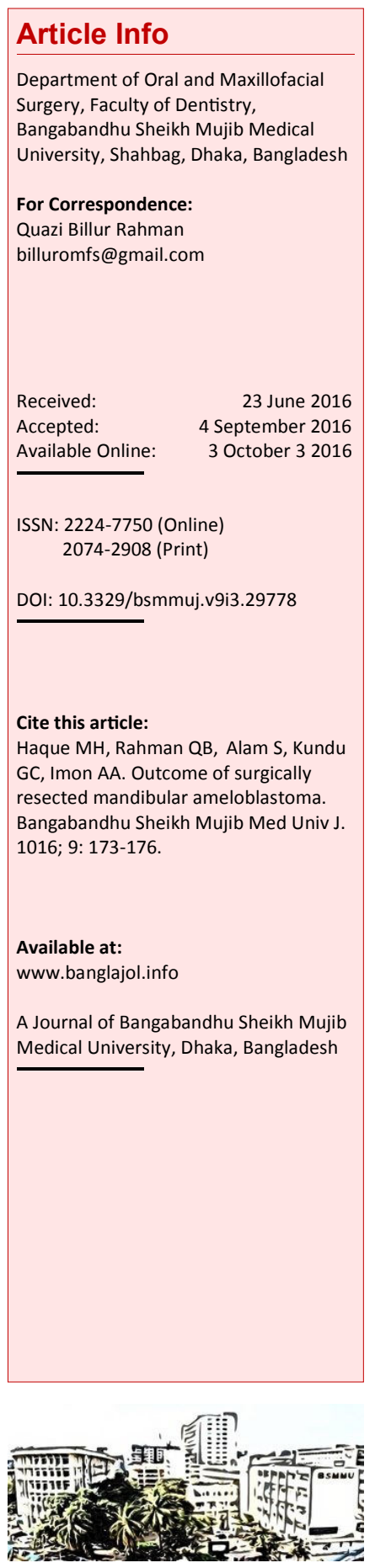

\section{Abstract}

The aim of the study was to establish the resection margin of mandible during ameloblastoma excision. In this study, 30 patients with ameloblastoma of the mandible were selected irrespective of age, sex, religion and socioeconomic status of the patient. Patients were divided into three groups. The tumors were resected with $0.5 \mathrm{~cm}$ (Group 1), $1 \mathrm{~cm}$ (Group 2) and $1.5 \mathrm{~cm}$ (Group 3) healthy bones. All the patients were treated either by marginal resection or segmental resection followed by reconstruction. Out of 10 patients in Group 1, two were found involved with tumor after resection of ameloblastoma. But in Group 2 and Group 3, margins were free from tumor at the resected margin. In conclusion, excision of ameloblastoma from mandible with $1 \mathrm{~cm}$ healthy bone is adequate to attain the resected margin tumor free.

\section{Introduction}

Ameloblastoma is a slow growing, locally invasive tumor. If the tumor not removed adequately, there may be chance of recurrence. But with virtually it has no tendency to metastasize. Failure to provide adequate treatment often resulting recurrence. 1 Ameloblastoma usually affects the maxilla and mandible and only about $1 \%$ of all jaw bone tumors. This type of tumor occurs only $11 \%$ of all odontogenic tumors.2 Ameloblastoma is of epithelial origin, which arises from enamel organ, dental follicle, periodontal ligament and lining of odontogenic (dentigerous) cyst. Ameloblastoma are classified into four groups: cystic, solid, peripheral and malignant. 3

Radiologically, it is a well-circumscribed unicystic or multicystic radiolucency and shows soap-bubble and honey-comb appearance. 4 Multicystic ameloblastoma can grow enormously sometimes and has a tendency to infiltrate into adjacent structures. It has the propensity to recur because numerous micro extensions projecting into the bone. 5 Multicystic ameloblastoma has a poorer prognosis than the unicystic lesion.

More conservative treatment modalities are curettage, enucleation and the dredging, the modified variation are previous one. These conservative modalities of treatment always have chance of recurrence. This disadvantage of conservative treatment leads to the radical surgery with a healthy margin. The procedure in which the ameloblastoma is removed with 1 $\mathrm{cm}$ healthy margin is defined as radical surgery.

The invasion of ameloblastoma occurs in the intertrabicular spaces of cancellous bone but erodes the compact bone without invasion. The ameloblastoma often extends into cancellous bone clinically, but appears not to be involved as observed in radiography. So, the chance of recurrence is profound in the surrounding bone, if the treatment modalities are considered as cure-ttage or enucleation. For this reason the excision margin of ameloblastoma should include beyond the extensive margin in compact bone of mandibular posterior and inferior limit according to the clinical and radiological assessment, will be considered the extension of mandible. $\underline{6}$

Sometimes the large tumor has a tendency to resort the cortical plate, the periosteum of mandible and surrounding soft tissues as well. So, the basic principle of the treatment of small, solid and multicystic ameloblastoma should be marginal resection with 1-1.5 healthy bony margin. 7 The treatment of ameloblastoma, still, has controversy regarding the resected margin clearance along with the different procedure of treatment modalities. Some author's considered healthy bony margin $3 \mathrm{~cm}$, the other described minimum 1.5 to $2 \mathrm{~cm}$ healthy margin for a better outcome of this tumor. 8 A study among 82 resected margin of ameloblastoma shows neoplasm extends up to 2 to $8 \mathrm{~mm}$ and no recurrence was noted with a follow-up of at least 5 years after radical surgery. 9 
Excision of excess bone will be unjustified and increased the morbidity of the patients. On the other hand, excision of inadequate healthy margin leads to recurrence of tumor. To overcome this controversy whether the resection margin will be up to $0.5 \mathrm{~cm}, 1 \mathrm{~cm}$ or $2 \mathrm{~cm}$ as a tumor free healthy margin during the surgical procedure, this study was justified.

\section{Materials and Methods}

This prospective study was done from June 2008 to June 2010. Thirty cases of ameloblastoma of the mandible were selected by the histopathological study of the tumor irrespective of age, sex, religion or socio-economic status of the patients and were arranged in three groups (10 in each group), on the basis of radiological assessment. Group 1: Excision of ameloblastoma of mandible with $0.5 \mathrm{~cm}$ healthy bone margin of the tumor end; Group 2: Excision of the ameloblastoma of mandible with $1 \mathrm{~cm}$ healthy bone margin of the tumor end; Group 3: Excision of the ameloblastoma of mandible with $1.5 \mathrm{~cm}$ healthy bone margin of the tumor end.

The extension of tumor of the jaw was determined first radiologically, then in operation theater after exposing the tumor. Radiologically one end of the tumor is demarcated after that another demarcation was made according to the grouping of patients either $0.5 \mathrm{~cm}$ or $1 \mathrm{~cm}$ or $1.5 \mathrm{~cm}$ from the $1 \mathrm{st}$ radiological demarcation. In the operation theater after exposure of the tumor correlation was made to determine the extension of the tumor. Then a demarcation line was made according to grouping either by $0.5 \mathrm{~cm}$ or by $1 \mathrm{~cm}$ or by $1.5 \mathrm{~cm}$ from the tumor margin with the help of the bar. Under general anesthesia resection of the mandible was done with osteotome according to last demarcation. The surgical specimen was fixed in $10 \%$ formalin and was sent for histopathological examination to assess whether a tumor was present or not in the proximal end of resected bone fragments.

\section{Results}

Seven patients out of 10 in Group I were treated by segmental resection of mandible and 3 were treated by marginal resection of mandible. In both cases, resection of ameloblastoma was done from mandible with $0.5 \mathrm{~cm}$ healthy bone margin beyond the radiological margin of the tumor. Six out of 10 in Group 2 were treated by segmental resection and 4 by marginal resection. In all the cases, resection of ameloblastoma was done from mandible with $1 \mathrm{~cm}$ healthy bone margin beyond the radiological margin of the tumor. In Group 3, 10 patients were included. 8 patients were treated by segmental resection and 2 by marginal resection. In all the cases, resection of ameloblastoma was done from mandible with $1.5 \mathrm{~cm}$ healthy bone margin beyond the radiological margin of the tumor.

X-ray showed the extension of the tumor up to the corresponding tooth (Table I). Two cases showed the extension from right lower 3rd molar to right lower 1st molar (Group 1) but none was found in Group 2 and Group 3.

The mean length was $8.3 \mathrm{~cm}$ in Group 1, $6.1 \mathrm{~cm}$ in Group 2 and $6 \mathrm{~cm}$ in Group 3. The mean length was not statistically significant $(p>0.05)$ among the groups.

Table II shows the marginal clearance of the lesion histopathologicaly, and tumor free margin was found in 8 cases (Group 1), 10 cases (Group 2) and 10 cases (Group 3) respectively. Margin involved was 2 in Group 1 and none was found in Group 2 and Group $3(p>0.05)$ that was not statistically significant.

The period of follow-up and found during $1-3$ months follow-up 3 in Group 1, 1 in Group 2 and none was found in Group 3. During 3-6 months follow-up it was observed 1 in Group 1, in Group 2 and 3 in Group 3. During 6-9 months follow-up it was observed 1 in Group 1, 2 in Group 2 and 2 in Group 3. During 9-12 months follow-up it was observed 3 in Group 1, 2 in Group 2 and 2 in Group 3. During 12-24 months follow-up it was observed 2 in Group 1, 2 in Group 2 and 3 in Group 3. This difference was not statistically significant $(\mathrm{p}>0.05)$ between 3 groups (Table III).

\section{Discussion}

After resection of tumor tissue the proximal end of the sample was sent to the histopathology department to identify the margin whether it was free from tumor or involved by the tumor. In Group 1, 10 patients sample was verified histologically, 2 of them were not free from the tumor tissue and 8 samples were free. In Group 2, 10 patient's samples was sent and all of them were free. In group 3, 10 patients sample was sent and all of them were free from tumor tissue. After the surgical resection, one year follow-up was done. Some complications were observed during this period wound dehiscence in case of 4 patients, exposure of the reconstruction plate in 3 patients. Fracture of the reconstruction plate in 2 patients, rejection of graft in 1 patient and have no recurrence.

Most of the surgeon considered the excision of a tumor by resection of mandible in case of ameloblastoma. Many other authors prefer $3 \mathrm{~cm}$ as an acceptable margin in case of resection of ameloblastoma and other recommended 1.5 to $2 \mathrm{~cm}$. On the other hand many authors believe that $3 \mathrm{~cm}$ 
Table I

Distribution of the cases according to extension of the tumor radiologically in relation to tooth

\begin{tabular}{|c|c|c|c|}
\hline Extension from & $\begin{array}{c}\text { Group 1 } \\
(\mathrm{n}=10)\end{array}$ & $\begin{array}{c}\text { Group 2 } \\
(\mathrm{n}=10)\end{array}$ & $\begin{array}{r}\text { Group 3 } \\
(\mathrm{n}=10)\end{array}$ \\
\hline Right lower 3rd molar to 1st molar & 2 & 0 & 0 \\
\hline Left lower 2nd premolar to mid ramus & 0 & 3 & 0 \\
\hline Right lower lateral incisor up to whole of the ramus & 0 & 2 & 4 \\
\hline Left lower canine up to whole of the ramus & 0 & 0 & 5 \\
\hline Left lower 1st premolar to left lower 3rd molar & 3 & 1 & 0 \\
\hline Right lower canine to right lower 3rd molar & 0 & 3 & 0 \\
\hline Right lower 1st premolar to left canine & 2 & 0 & 0 \\
\hline Right lower 2nd molar to left lower 3rd molar & 1 & 1 & 0 \\
\hline Right lower canine to $3 \mathrm{rd}$ molar & 2 & 0 & 1 \\
\hline
\end{tabular}

\section{Table II}

Distribution of the patients according to marginal clearance

\begin{tabular}{|l|ccc|}
\hline Marginal clearance & $\begin{array}{c}\text { Group 1 } \\
(\mathrm{n}=10)\end{array}$ & $\begin{array}{c}\text { Group 2 } \\
(\mathrm{n}=10)\end{array}$ & $\begin{array}{c}\text { Group 3 } \\
(\mathrm{n}=10)\end{array}$ \\
\hline Margin free & 8 & 10 & 10 \\
Margin involve & 2 & 0 & 0 \\
\hline
\end{tabular}

is the most acceptable linear margin while others recommend at least $1.5 \mathrm{~cm}$ or $2 \mathrm{~cm}$ bony margin for the cure of this neoplasm. A study was done among 82 cases of ameloblastoma, resection margin shows neoplasm extends up to 2 to $8 \mathrm{~mm}$ and no recurrence was noted with a follow-up of at least 5 years.10 It is safe to resected margin not less than $1 \mathrm{~cm}$ but not more than $1.5 \mathrm{~cm}$ healthy bone of mandible away from the radiological demarcation of tumor. In another finding shows that the extension of tumor in which cancellous bone average $4.5 \mathrm{~mm}$, the other results shows are 2.3-8 $\mathrm{mm}$ in radiologically. These authors preferred surgical resection margins about 1 to $1.5 \mathrm{~cm}$. $\underline{11}$ Peroperative frozen sections is used for sampling and assessing tumor free margins, ensure adequate resection of neoplasm, with accuracy approximately 95\%.12-14 In 61 cases of ameloblastoma $1 \mathrm{~cm}$ surgical margin of cancellous bone from mandible was removed and examine by frozen section peroperatively and was analyzed and compared with post de-calcification histology. 15 Currently it has recommended that the surgical resection of amelo-
Table III

\section{Distribution of the patients according to} period of follow-up

\begin{tabular}{|cccc|}
$\begin{array}{c}\text { Period of follow-up } \\
\text { (months) }\end{array}$ & $\begin{array}{c}\text { Group 1 } \\
(\mathrm{n}=10)\end{array}$ & $\begin{array}{c}\text { Group 2 } \\
(\mathrm{n}=10)\end{array}$ & $\begin{array}{c}\text { Group 3 } \\
(\mathrm{n}=10)\end{array}$ \\
\hline $1-3$ & 3 & 1 & 0 \\
$3-6$ & 1 & 3 & 3 \\
$6-9$ & 1 & 2 & 2 \\
$9-12$ & 3 & 2 & 2 \\
$12-24$ & 2 & 2 & 3 \\
\hline
\end{tabular}

blastoma should be at least $1-2 \mathrm{~cm}$ margin.1,10,16 and immediate bony reconstruction..$\underline{16,17}$

According to this study in 2 cases, tumor was positive in Group I, where the healthy margin clearance was up to $0.5 \mathrm{~cm}$, probably because the healthy margin clearance was not enough. On the other hand in Group 1 and 2, when the healthy resected bone margin was considered up to $1 \mathrm{~cm}$ and $1.5 \mathrm{~cm}$ respectively. So, it is clear that where the resected margin was taken more than $0.5 \mathrm{~cm}$, it was enough as tumor free margin.

\section{Conclusion}

According to the outcome of this study it would be preferable to establish the tumor free margin not less than $1 \mathrm{~cm}$ during the surgical procedure not only prevent the recurrence but also reduce the surgical morbidity. 


\section{References}

1. Apple BN, Verbin RS. Odontogenic tumours. In: Surgical pathology of the head and neck. Barnes El (ed). New York, Marcel Dekker, 1985, pp 1331409.

2. Carlson ER, Marx RE. The ameloblastoma: Primary, curative surgical management. J Oral Maxillofac Surg. 2006; 64: 484-94.

3. Carlson ER. Ameloblastoma. Symposium on odontogenic tumours. AAOMS 82ndAnnual Meeting and Scientific Session, San Francisco, CA 2000.

4. Collings SJ. Harrison. A recurrent ameloblastoma: A historic case report and review of the literature. Br Dental J. 1993; 174: 202-06.

5. Forrest LA, Schuller DE, Karanfilov B, Lucas JG. Update on intraoperative analysis of mandibular margins. Am J Otolaryngol. 1997; 18: 396-99.

6. Gardner DG, Pecak AMJ. The treatment of ameloblastoma based on pathologic and anatomic principles. Cancer 1980; 46: 2514-19.

7. Gephardt GN, Zarbo RJ. Interinstitutional Comparison of frozen section conultations. Arch Pathol Lab Med. 1996; 120: 804-09.

8. Gold L. Biologic behavior of ameloblastoma. Oral Maxillofacial Surg. 1991; 3: 21.

9. Gorlin RJ, Chaudhry AP, Pindborg JJ. Odontogenic tumours: Classification, histopathology and clinical behavior in man and domesticated animals. Cancer 1961; 14: 73-110.

10. Kramer IRH. Ameloblastoma: A clinicpathological appraisal. Br J Oral Surg. 1963; I: 13-28.

11. Marx RE, Smith BH, Smith BR, Fridrich KL. Swelling of the retromolar region and cheek associated with limited opening. J Oral Maxillofac Surg. 1993; 51: 304-09.

12. Muller H, Slootweg PJ. The growth characteristics of multilocular ameloblastoma. J. Maxillofacial Surg. 1985; 13: 224-30.

13. Muller H, Slootweg PJ. The ameloblastoma: The controversial approach to therapy. J Maxillofacial Surg. 1985; 13: 79.

14. Sham E, Leong J, Maher R, Schenberg M, Leung $\mathrm{M}$, et al. Mandibular ameloblastoma: Clinical experience and literature review. ANZ J Surg. 2009; 79: 739-44.

15. Tsai CY, Wei FC, Chang YL, Chen YY, Chen CT. Vastus lateralis muscle flap used for reconstruction of the maxilla after radical resection of recurrent ameloblastoma. Chang Gung Med J. 2006; 29: 331-35.

16. Williams TP. Management of ameloblastoma: A changing perspective. J Oral Maxillofac Surg. 1993; 51: 1064-70.

17. Winther C, Graem N. Accuracy of frozen section diagnosis: A retrospective analysis of 4785 cases. APMIS. 2011; 119: 259-62. 